\title{
Network meta-analysis of antiplatelet therapy following coronary artery bypass grafting (CABG): none versus one versus two antiplatelet agents
}

\author{
Adam Chakos ${ }^{1}$, Dean Jbara ${ }^{1 \#}$, Kamal Singh ${ }^{1 \#}$, Tristan D. Yan ${ }^{1,2,3}$, David H. Tian ${ }^{1,4}$ \\ ${ }^{1}$ The Collaborative Research (CORE) Group, Macquarie University, Sydney, Australia; ${ }^{2}$ Faculty of Medicine and Health Sciences, Macquarie \\ University, Sydney, Australia; ${ }^{3}$ Department of Cardiothoracic Surgery, Royal Prince Alfred Hospital, Sydney, Australia; ${ }^{4}$ Royal North Shore Hospital, \\ Sydney, Australia \\ \#These authors contributed equally to this work. \\ Correspondence to: Adam Chakos. The Collaborative Research (CORE) Group, Macquarie University, Sydney, Australia. Email: adam.chakos@outlook.com.
}

Background: Numerous agents have been trialed following coronary artery bypass grafting (CABG) to maintain long-term graft patency. While clear evidence exists for the use of aspirin in maintaining graft patency, the role of dual-antiplatelet therapy in CABG patients is not as well established. This network meta-analysis aimed to compare the short-term post-CABG graft patency outcomes for patients with none, one or two antiplatelet agents.

Methods: Electronic databases were queried for randomized controlled trials comparing CABG graft patency rates at three months and beyond using various antiplatelet agents or placebo. Drug and graft patency data were compared using a mixed treatment comparison under a Bayesian hierarchical framework. A random-effects consistency model was applied. Direct and indirect comparisons were made between drugs and used to determine the relative efficacy for graft patency.

Results: The literature search identified 16 papers fulfilling the inclusion criteria, including a total of 3,133 patients with an average of 2.43 [95\% confidence interval (CI): 2.20-2.66] grafts per patient. Graft types were incompletely reported, however, saphenous vein grafts (SVGs) were predominantly used [where specifically reported: 4,490 SVG, 1,226 internal mammary artery (IMA) grafts]. In all, five different agents and placebo in various regimens were compared by results of angiographic follow-up conducted at a mean of 10.4 months (95\% CI: 9.28-11.5 months). Compared to placebo, aspirin alone [odds ratio (OR) 1.9; 95\% credible interval (CrI): 1.3-2.8], aspirin + dipyridamole (OR 1.9; 95\% CrI: 1.3-2.6), aspirin + clopidogrel (OR 2.9; 95\% CrI: 1.5-5.7) and aspirin + ticagrelor (OR 3.8; 95\% CrI: 1.2-13.0) significantly improved graft patency. When compared to aspirin monotherapy, aspirin + clopidogrel (OR 1.6; 95\% CrI: 0.86-2.7) and aspirin + ticagrelor (OR 2.0; 95\% CrI: 0.69-6.3) had OR that suggested a trend favoring patency compared to aspirin monotherapy, however, these results did not reach significance. Sub-group analysis of SVG graft patency was unable to reach significance (only eight studies with six treatment comparisons were evaluated). Secondary endpoints of death, bleeding, myocardial infarction and cerebrovascular accident were incompletely reported and were pooled but not compared between drug treatment arms.

Conclusions: Aspirin monotherapy and dual antiplatelet therapy (DAPT) provided significant all-graft patency benefit compared to placebo at three months and beyond. A trend existed for DAPT to improve graft patency compared to aspirin, although this did not reach statistical significance. Further randomized controlled studies comparing aspirin monotherapy to DAPT are required to determine the utility of DAPT in CABG patients for maintaining graft patency.

Keywords: Antiplatelet; graft patency; dual antiplatelet therapy (DAPT); coronary artery bypass graft; network meta-analysis

Submitted Aug 20, 2018. Accepted for publication Sep 05, 2018.

doi: 10.21037 /acs.2018.09.02

View this article at: http://dx.doi.org/10.21037/acs.2018.09.02 


\section{Introduction}

A multitude of different agents have been used following coronary artery bypass grafting (CABG) to improve graft patency rates. These treatments have included both monotherapies (commonly aspirin) and more recently, dual therapies (aspirin in conjunction with another anti-platelet agent) $(1,2)$. Other monotherapies have also been trialed, including the use of anti-coagulants alone $(3,4)$, however, these have not been widely adopted.

While the use of dual anti-platelet therapy (DAPT) in coronary percutaneous intervention (PCI) patients is considered the standard of care for maintaining graft patency and reducing post-procedural ischaemic events, the role for DAPT in post-operative CABG patients is not as clearly established $(1,5,6)$. Meta-analyses have investigated the impact on graft patency of aspirin use compared to placebo (7), as well as dual antiplatelet use compared to aspirin alone $(1,8,9)$ in patients following CABG. These showed that aspirin monotherapy was superior to placebo and that DAPT was superior to aspirin monotherapy for saphenous vein grafts but was not significantly better when arterial grafts were included $(8,9)$. While these meta-analyses have compared placebo with aspirin and aspirin with DAPT individually, there is a paucity of direct comparisons between all agents. This network meta-analysis aims to summarize the relative efficacies for maintaining graft patency when using none, one or two antiplatelet agents following CABG.

\section{Methods}

\section{Literature search}

Three electronic databases (MEDLINE, Embase and PubMed) were queried from their dates of inception till March 2018 using the search terms (("CABG" OR "coronary artery bypass" OR "coronary bypass" OR "coronary artery bypass graft") AND ("anti-platelet" OR "aspirin" OR “clopidogrel” OR "ticagrelor" OR "plavix" OR “prasugrel” OR “antiplatelet”) AND ("randomized controlled trial" OR "randomised controlled trial" OR “RCT" OR "Randomized" OR "Randomised")). Randomized controlled trials with an intention to treat of at least 50 patients per arm and examining graft patency with at least 3-month follow-up were included. Studies which were not randomized controlled trials, were animal studies or did not have English language full texts were excluded. Non-binary patency data (such as graft patency reported by flow in milliliters/minute), unclear graft patency reporting and early study termination [incomplete randomised controlled trials (RCTs)] led to the study being excluded. Studies or study arms containing drugs not used contemporarily for graft patency and reported only in single studies (such as warfarin alone) were excluded. Where the same cohort of patients was reported in multiple articles, only the latest cohort data was included.

The primary outcome was graft patency in the (3-month or beyond) follow-up period, with secondary outcomes including mortality, bleeding, myocardial infarct and cerebrovascular accident. Literature search and data collection were performed by two independent researchers (D Jbara and K Singh). A further reference list search was conducted for the included papers. The search process is shown in supplementary Figure S1.

\section{Quality analysis}

Appraisal of randomized controlled trial study quality was conducted using a binary scoring system with twenty categories adapted from the Consolidated Standards of Reporting Trials statement 2010 (CONSORT 2010) (10). Using this scale, study quality was stratified as standard and high quality, with studies scoring in the range 12-16 standard quality and 16-20, high quality.

\section{Surgical procedures, dosing and follow-up}

CABG in included studies utilised both venous and arterial conduits, harvested using both open and endoscopic methods. Surgery was performed using both on-pump and off-pump (OPCAB) techniques through a median sternotomy. Minimally-invasive direct coronary artery bypass (MIDCAB) or total endoscopic coronary bypass (TECAB) was not used.

Dosing of anti-platelet (and where used, anti-coagulants) was commenced according to a number of different criteria between studies, including thresholds based on time, pericardial drain rate, drain removal and/or ability to take oral medications. Dose amount and frequency varied according to study.

Assessment of patency at follow-up was performed using either invasive angiography or non-invasive computed tomographic angiography (CTA). The degree of stenosis for each followed-up case was determined from angiography. Methods such as fractional flow reserve (FFR) were not recorded. 


\begin{tabular}{|c|c|}
\hline Parameter & Pooled data \\
\hline Patients, $n$ & 3,133 \\
\hline Males, n (\%) & $2,715(87 \%)$ \\
\hline Age, mean $(95 \% \mathrm{Cl})$ & $56.4(55.7-57.1)$ \\
\hline $\begin{array}{l}\text { Smoking history, } \\
\mathrm{n}[\%(95 \% \mathrm{Cl})]\end{array}$ & $1,468 / 2,494[52.5(44.1-60.9)]$ \\
\hline $\begin{array}{l}\text { Hypertension, } \\
\text { n [\% (95\% Cl)] }\end{array}$ & $1,107 / 2,833[39.0(33.3-45.0)]$ \\
\hline $\begin{array}{l}\text { Hypercholesterolaemia, } \\
\mathrm{n}[\%(95 \% \mathrm{CI})]\end{array}$ & $648 / 1,476$ [47.5 (37.5-57.7)] \\
\hline $\begin{array}{l}\text { Diabetes mellitus, } \\
\mathrm{n}[\%(95 \% \mathrm{Cl})]\end{array}$ & $390 / 1,724$ [21.9 (15.4-30.0)] \\
\hline $\begin{array}{l}\text { Previous myocardial infarction, } \\
\mathrm{n}[\%(95 \% \mathrm{Cl})]\end{array}$ & $1,026 / 2,154[46.8(41.6-52.0)]$ \\
\hline Angina, $\mathrm{n}[\%(95 \% \mathrm{Cl})]$ & $1,609 / 1,883$ [86.4 (74.7-93.2)] \\
\hline Grafts, n & 6,667 \\
\hline $\begin{array}{l}\text { Grafts per patient, } \\
\text { mean }(95 \% \mathrm{Cl})\end{array}$ & $2.43(2.20-2.66)$ \\
\hline
\end{tabular}

\section{Statistical methods}

Baseline data was pooled using meta-analysis of means or proportions, with individual study effect size accounted for using inverse variance methods in a random-effects model. Only data present in more than $50 \%$ of included studies were included. Values that were reported as median and range or interquartile range were converted to mean and standard deviation $(11,12)$. All data are displayed as raw values as well as percentages with $95 \%$ confidence intervals (CIs) or $95 \%$ credible intervals (CrI) (as appropriate).

Latest follow-up of per-patient, per-graft and peranastomosis patency data was collected and the most complete dataset used for network meta-analysis comparing drugs. Where follow-up data was reported as occlusion only, patency was calculated by taking the complement of the grafts occluded.

Arm-level patency data was analysed across all studies, with direct and indirect comparisons of pooled placebo, anti-platelet and anti-coagulant regimes made using a mixed treatment comparison based on a Bayesian hierarchical model. This model was implemented using a Markov Chain Monte Carlo simulation within the gemtc package in $\mathrm{R}[\mathrm{R}$ Foundation for Statistical Computing, Vienna, Austria (13)]
$(14,15)$. Given the range of drugs, dosing regimens, graft types and time period over which included studies were conducted, a random effects model was used. For the purposes of the mixed-treatment comparison, consistency in direct and indirect effects was assumed (16). Heterogeneity between comparisons within the network was analysed by examining $\mathrm{I}^{2}$ values for the random-effects model and inconsistency was examined both graphically (between pair-wise and network results) and using a node-splitting analysis. Where direct comparisons were contributed to by at least two studies, $\mathrm{I}^{2}$ was calculated to investigate heterogeneity as a source of variability in results.

Odds ratios were calculated for graft patency and findings were taken as significant where the $95 \% \mathrm{CrI}$ did not include unity. Node-splitting analysis used within this study considered $\mathrm{P}$ values less than 0.05 as significant for inconsistency between included studies.

\section{Results}

The literature search identified 2,554 records, of which 16 matched the inclusion criteria. According to the CONSORT tool, 11 studies were deemed high quality and five studies standard quality. These consisted of 13 twoarmed trials $(3,4,17-27)$, two three-armed trials $(28,29)$ and one four-armed trial (30).

Overall, 3,133 patients were included, with an average of 2.43 (95\% CI: 2.20-2.66) grafts per-patient. Saphenous vein, internal mammary artery and radial artery conduits were used, however, exact numbers of each conduit type were not fully reported for all papers. Graft target vessels were also incompletely reported. Angiographic patency at follow-up was reported for all grafts and was used in the mixed treatment comparison. Mean followup for coronary angiography (using invasive or CTA) across studies was 10.4 (95\% CI: 9.28-11.5) months (minimum follow-up of 3 months). Pooled patient data and baseline risk factors are presented in Table 1; individual study and patient baseline data is provided in Supplementary Tables $S 1, S 2$.

Drugs trialed to improve patency outcomes included aspirin monotherapy (ASA), aspirin + dipyridamole, aspirin + clopidogrel, aspirin + ticagrelor and clopidogrel monotherapy. Dosing amounts and regimes varied between studies and are detailed in supplementary Table S1. It was assumed that any impact from differences in dose amount and frequency for the same drug between studies would be visible by differences in outcomes within groups of the 
network meta-analysis.

Graft details and follow-up graft patency/occlusion data is presented in supplementary Table $S 3$. The network model for the mixed treatment comparison of graft patency is shown in Figure 1.

Summary results for all treatments' patency at followup is shown in Figure 2, with placebo and aspirin used as references. These pooled results show aspirin monotherapy and dual antiplatelet therapies (aspirin combination therapies) are superior to placebo. Aspirin in combination with dipyridamole achieved almost identical patency results to aspirin alone. Summary of relative effects is shown in Table 2.

Rank probability analysis for graft patency at follow-up (Figure 3) demonstrated dual anti-platelet therapies with ticagrelor or clopidogrel (as the agent in addition to aspirin)

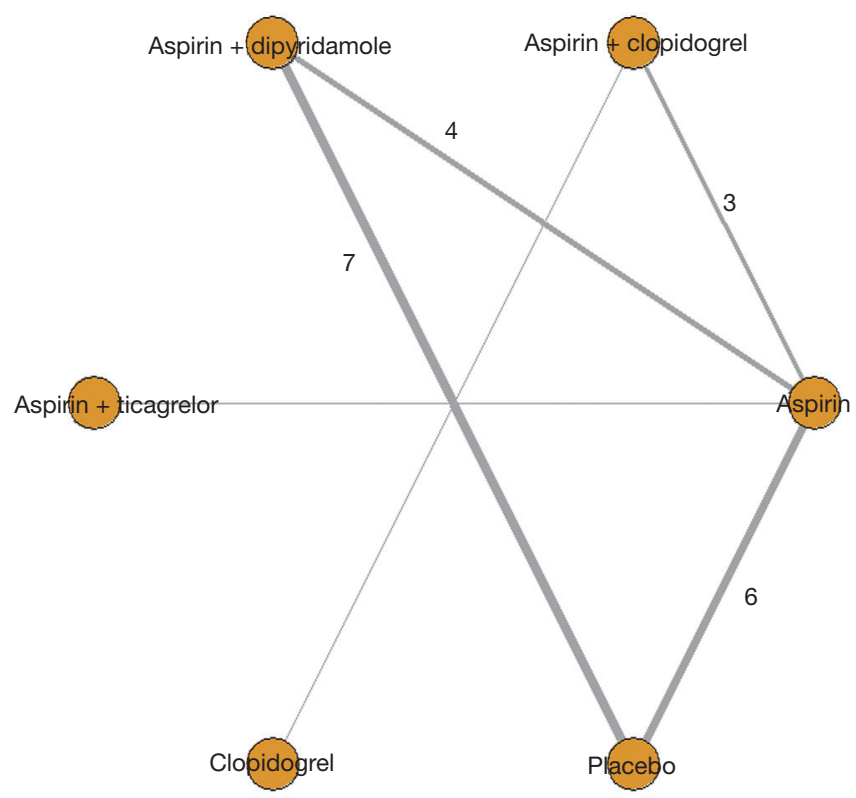

Figure 1 Network diagram of treatments and direct comparisons available from included studies. The thickness of the links between treatments reflects the number of studies in that link (annotated for all links with more than one study).

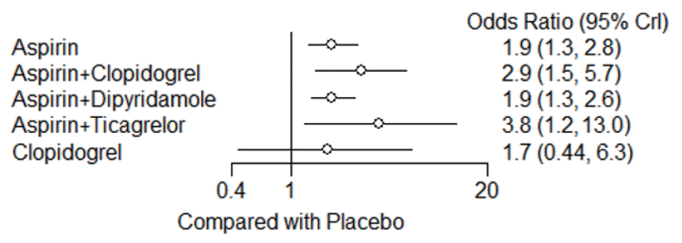

had higher probabilities of being the first and second most effective treatments, respectively. Aspirin with dipyridamole and aspirin monotherapy were likely to rank approximately equal third and fourth from included treatments for maintaining graft patency at follow-up. Placebo had the highest probability for ranking as least effective in maintaining graft patency at follow-up.

Direct, pairwise, indirect (where indirect evidence was available) and pooled/network mixed-treatment comparisons for graft patency at follow-up are shown in supplementary Figure $S 2$. $\mathrm{I}^{2}$ demonstrated heterogeneity was moderate $\left(\mathrm{I}^{2}>50 \%\right)$ in comparisons of placebo and aspirin + dipyridamole and was low for the placebo versus aspirin comparison $\left(\mathrm{I}^{2}>25 \%\right)$. Heterogeneity was minimal $\left(\mathrm{I}^{2}=0 \%\right)$ for comparison of aspirin + clopidogrel and aspirin and for comparison of aspirin + dipyridamole and aspirin. Separate node splitting analysis demonstrated that inconsistency was low within treatment comparisons.

A sub-group analysis of eight included studies (containing 6 treatment comparisons) was conducted for saphenous vein graft patency. Only aspirin + dipyridamole reached significance for graft patency benefit compared to placebo (OR 2.5; 95\% CrI: 1.1-5.9). The DAPT treatments were not shown as significantly better than aspirin monotherapy, however, this analysis was likely limited by sparse results (supplementary Figure S3).

Secondary outcomes were sparsely reported in included studies: follow-up death was reported in only $78 \%$ of studies, bleeding in $39 \%$ of studies, myocardial infarction in $47 \%$ of studies and cerebrovascular accident in $31 \%$ of studies. The pooled proportions of secondary outcomes reported are summarized in Table 3, individual study outcomes are reported in Supplementary Table S4. Network meta-analysis was not conducted for secondary outcomes.

\section{Discussion}

This network meta-analysis aimed to compare graft patency

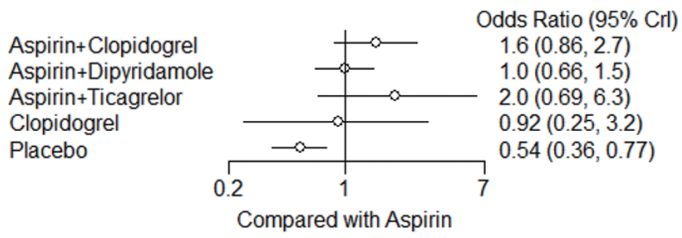

Figure 2 Network meta-analysis results for patency at follow-up with placebo and aspirin (ASA) used as reference (none versus one versus two antiplatelet agent comparison). 


\begin{tabular}{|c|c|c|c|c|c|c|}
\hline $\begin{array}{l}\text { Patency drugs } \\
\text { (control) }\end{array}$ & \multicolumn{6}{|l|}{ Experiment } \\
\hline Aspirin & - & $1.56(0.86,2.72)$ & $1.00(0.66,1.51)$ & $2.02(0.69,6.26)$ & $0.92(0.25,3.2)$ & $0.54^{*}(0.36,0.77)$ \\
\hline $\begin{array}{l}\text { Aspirin + } \\
\text { dipyridamole }\end{array}$ & $1.00(0.66,1.51)$ & $1.56(0.75,3.12)$ & - & $2.02(0.64,6.74)$ & $0.92(0.23,3.43)$ & $0.54^{*}(0.38,0.74)$ \\
\hline $\begin{array}{l}\text { Aspirin + } \\
\text { ticagrelor }\end{array}$ & $0.49(0.16,1.44)$ & $0.77(0.22,2.55)$ & $0.50(0.15,1.55)$ & - & $0.45(0.08,2.35)$ & $0.26^{\star}(0.08,0.82)$ \\
\hline
\end{tabular}

results at least 3 months after CABG given the use of none, one or two anti-platelet agents to give context to the application of single or DAPT by the surgeon today. Results from 16 studies and 6,667 followed-up grafts demonstrated aspirin monotherapy, aspirin + dipyridamole and DAPT (aspirin + clopidogrel, aspirin + ticagrelor) following CABG all achieved significant patency benefit compared to placebo. A trend existed that favored DAPT over aspirin alone, although this was not statistically significant. While aspirin + ticagrelor had the highest probability being ranked the best therapeutic option, it should be noted that this was based on a single study (27).

While the superiority of DAPT over aspirin monotherapy (or aspirin + dipyridamole) did not reach significance (including in the SVG sub-analysis), this finding contrasts with recent meta-analyses of single versus dual antiplatelet therapy which showed patency benefit of DAPT over aspirin monotherapy for saphenous vein grafts $(8,9)$. The reduced likelihood of a patency benefit for DAPT with arterial grafts likely occurs because arterial conduits are less prone to intimal hyperplasia and atherosclerosis (8). Given studies in the present analysis for DAPT included both saphenous vein and arterial conduits, it is not surprising that the inclusion of arterial conduits in pooling would attenuate the patency benefit of DAPT compared to if only SVG were being examined. Additionally, the SVG sub-group patency analysis in the present study may not have contained sufficient data to reach significance (as evidenced by wider credible intervals compared to the all-graft analysis for the same treatments and by the failure of aspirin monotherapy and DAPT to reach benefit over placebo). The pooling of arterial and venous graft patency results is appropriate given that grafting for multi-vessel disease typically involves both arterial and SVG conduits, as well as the growing trend towards total arterial revascularisation (31-33).

The results of the present analysis are in line with the 2016 American College of Cardiology/American Heart Association (ACC/AHA) guidelines for duration of DAPT in patients with coronary artery disease (34), which recommend aspirin use to promote graft patency (and continuation of DAPT where it was given for acute coronary syndrome or previous coronary stents). With regard to composite (non-patency) outcomes, the ACC/ AHA and European Society of Cardiologists (ESC) guidelines note that DAPT commenced for acute coronary syndrome should be recommenced post-CABG $(34,35)$.

Further contemporary arguments for the use of DAPT include that it may confer patency benefit in off-pump CABG patients and may reduce the incidence of major adverse cardiac events, particularly in hypercoagulable or aspirin-resistant patients $(5,24,36)$. While patency benefit has been shown with DAPT for venous grafts in off-pump patients (24), this benefit is not clear according to other DAPT versus monotherapy trials in off-pump patients (37) and a sub-analysis of 953 patients from a trial randomizing 


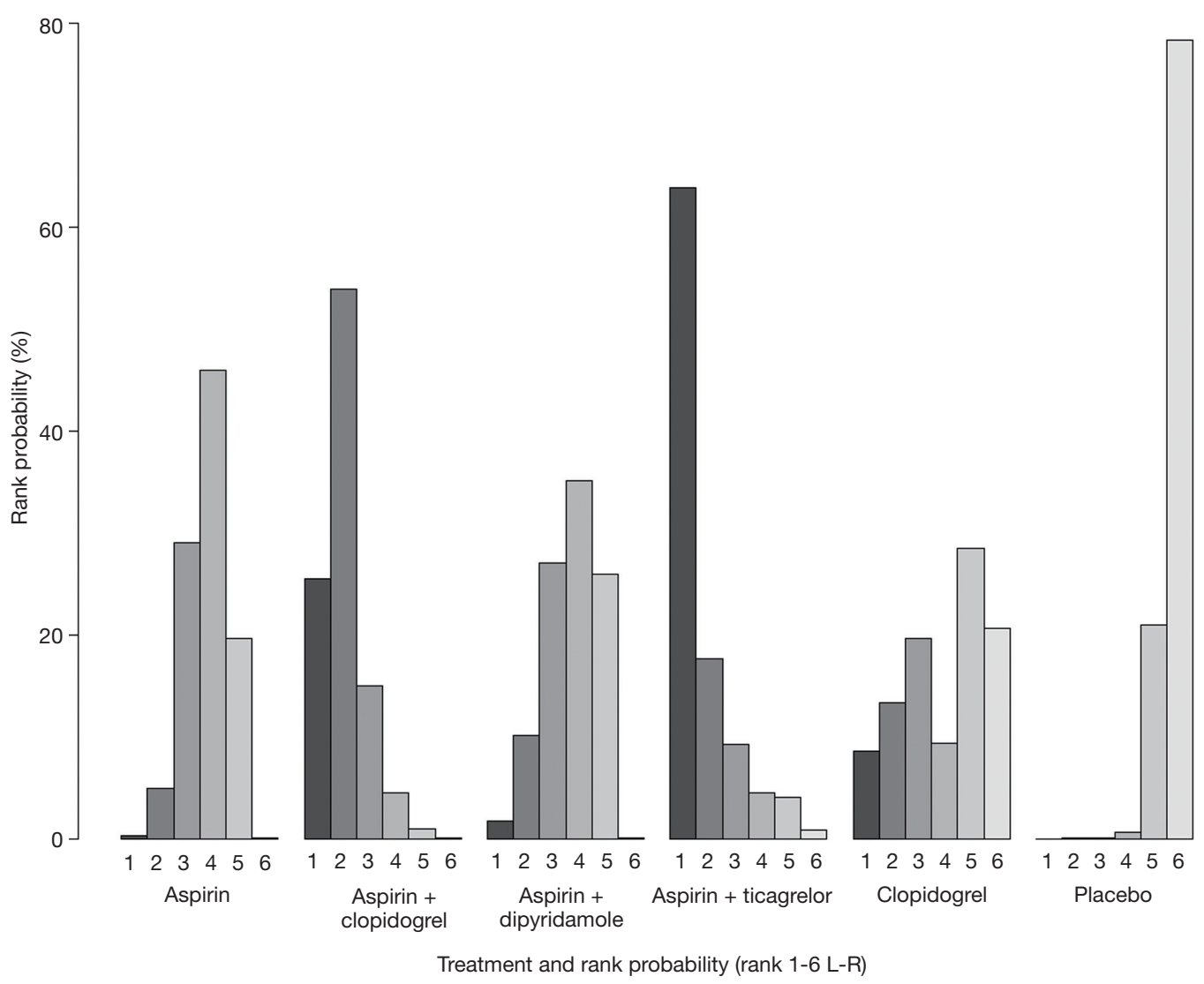

Figure 3 Rank probability for graft patency at follow-up. The probability of each treatment ranking as most effective ( $\left.1^{\text {st }}\right)$ to least effective $\left(6^{\text {th }}\right)$ is shown. For example, aspirin + ticagrelor has $65 \%$ probability of ranking as the most effective treatment $\left(1^{\text {st }}\right)$ and an approximately $1 \%$ probability as ranking as the least effective $\left(6^{\text {th }}\right.$ best $)$ treatment.

Table 3 Pooled proportions of secondary outcomes at follow-up across all studies

\begin{tabular}{ll}
\hline Outcomes & $\mathrm{n}[\%(95 \% \mathrm{Cl})]$ \\
\hline Death & $45 / 2,422[2.45(1.77-3.38)]$ \\
\hline Bleeding & $45 / 1,484[3.36(2.17-5.16)]$ \\
\hline Myocardial infarction & $64 / 1,575[3.96(2.55-6.11)]$ \\
\hline Cerebrovascular accident & $11 / 670[2.28(1.28-3.68)]$ \\
\hline
\end{tabular}

to on- and off-pump CABG (38). Reduced incidence of major adverse cardiac events (angina, myocardial infarction) was identified as a benefit of DAPT over aspirin monotherapy in a meta-analysis of RCT and institutional series, however, this may come at the expense of increased likelihood of major bleeding episodes (8). A trend towards increased major bleeding with DAPT was identified in a recent meta-analysis of bleeding from RCTs only, however, it did not reach statistical significance (risk ratio $1.28 ; 95 \%$ CI: 0.95-1.71), $\mathrm{P}=0.842$, favoring monotherapy for reduced bleeding) (39). Other meta-analyses examining a composite endpoint (death, myocardial infarction, stroke) also identified improvement in composite endpoint outcomes with DAPT and again, a non-significant increased risk ratio for bleeding (1).

Limitations of this study included the paucity of RCT evidence for graft patency following CABG with various agents, particularly with respect to contemporary application of DAPT using aspirin + clopidogrel (three included studies) or aspirin + ticagrelor (one included study). This is a potential source of under-powering and increases heterogeneity where there is variability between patency results. Many other sources of heterogeneity 
such as drug dosage and operative technique were also likely present. This study also excluded graft patency agents in studies (or arms of studies) that are not used contemporarily or only had a single contributing study (for example, warfarin, sulfinpyrazone, ticlopidine $(3,4,30,40)$. Furthermore, as the included studies were published between 1981 and 2016, corresponding improvements in patency outcomes could be expected to vary over time due to operative improvements and differing patient selection, potentially favoring contemporary therapeutic agents.

\section{Conclusions}

The present network meta-analysis showed clear evidence for improved patency compared to placebo at follow-up beyond three months exists for aspirin monotherapy and dual antiplatelet therapies with aspirin. The results also demonstrated that while DAPT may confer some patency benefit over aspirin monotherapy, this was not statistically significant. Results from further randomized controlled trials are required to evaluate the relative benefit of DAPT over aspirin monotherapy.

\section{Acknowledgements}

None.

\section{Footnote}

Conflicts of Interest: The authors have no conflicts of interest to declare.

\section{References}

1. Agarwal N, Mahmoud AN, Patel NK, et al. Metaanalysis of aspirin versus dual antiplatelet therapy following coronary artery bypass grafting. Am J Cardiol 2018;121:32-40.

2. Bhatt DL, Chew DP, Hirsch AT, et al. Superiority of clopidogrel versus aspirin in patients with prior cardiac surgery. Circulation 2001;103:363-8.

3. McEnany MT, Salzman EW, Mundth ED. The effect of antithrombotic therapy on patency rates of saphenous vein coronary artery bypass grafts. J Thorac Cardiovasc Surg 1982;83:81-9.

4. Van Der Meer J, Brutel de la Riviere A, Van Gilst WH, et al. Effects of low dose aspirin ( $50 \mathrm{mg} /$ day), low dose aspirin plus dipyridamole, and oral anticoagulant agents after internal mammary artery bypass grafting: Patency and clinical outcome at 1 year. J Am Coll Cardiol 1994;24:1181-8.

5. Rafiq S, Johansson PI, Kofoed KF, et al. Thrombelastographic hypercoagulability and antiplatelet therapy after coronary artery bypass surgery (TEGCABG trial): a randomized controlled trial. Platelets 2017;28:786-93.

6. Verma S, Goodman SG, Mehta SR, et al. Should dual antiplatelet therapy be used in patients following coronary artery bypass surgery? A meta-analysis of randomized controlled trials. BMC Surg 2015;15:112.

7. Okrainec K, Platt R, Pilote L, et al. Cardiac medical therapy in patients after undergoing coronary artery bypass graft surgery: A review of randomized controlled trials. J Am Coll Cardiol 2005;45:177-84.

8. Deo Salil V, Dunlay Shannon M, Shah Ishan K, et al. Dual Anti-platelet Therapy After Coronary Artery Bypass Grafting: Is There Any Benefit? A Systematic Review and Meta-Analysis. J Card Surg 2013;28:109-16.

9. Nocerino AG, Achenbach S, Taylor AJ. Meta-analysis of effect of single versus dual antiplatelet therapy on early patency of bypass conduits after coronary artery bypass grafting. Am J Cardiol 2013;112:1576-9.

10. Schulz KF, Altman DG, Moher D. CONSORT 2010 statement: updated guidelines for reporting parallel group randomised trials. BMC Med 2010;8:18.

11. Hozo SP, Djulbegovic B, Hozo I. Estimating the mean and variance from the median, range, and the size of a sample. BMC Med Res Methodol 2005;5:13.

12. Wan $X$, Wang W, Liu J, et al. Estimating the sample mean and standard deviation from the sample size, median, range and/or interquartile range. BMC Med Res Methodol 2014;14:135.

13. R: A language and environment for statistical computing. Vienna, Austria: R Foundation for Statistical Computing; 2016. 2016. Available online: https://www.r-project.org/

14. van Valkenhoef G, Kuiper J. Gemtc: network meta-analysis using Bayesian methods. 2014. R package version 06-1. Available online: https://cran.r-project.org/web/packages/ gemtc/gemtc.pdf

15. Plummer M. JAGS: A program for analysis of Bayesian graphical modeling using Gibbs sampling [computer program]. 2017. Available online: https://www.r-project. org/conferences/DSC-2003/Proceedings/Plummer.pdf

16. van Valkenhoef G, Lu G, de Brock B, et al. Automating network meta-analysis. Res Synth Methods 2012;3:285-99.

17. Brooks N, Wright J, Sturridge M, et al. Randomised 
placebo controlled trial of aspirin and dipyridamole in the prevention of coronary vein graft occlusion. Br Heart J 1985;53:201-7.

18. Chesebro JH, Fuster V, Elveback LR, et al. Effect of dipyridamole and aspirin on late vein-graft patency after coronary bypass operations. N Engl J Med 1984;310:209-14.

19. Gao C, Ren C, Li D, et al. Clopidogrel and aspirin versus clopidogrel alone on graft patency after coronary artery bypass grafting. Ann Thorac Surg 2009;88:59-62.

20. Gao G, Zheng Z, Pi Y, et al. Aspirin plus clopidogrel therapy increases early venous graft patency after coronary artery bypass surgery: A single-center, randomized, controlled trial. J Am Coll Cardiol 2010;56:1639-43.

21. Guiteras P, Altimiras J, Aris A, et al. Prevention of aortocoronary vein-graft attrition with low-dose aspirin and triflusal, both associated with dipyridamole: A randomized, double-blind, placebo-controlled trial. Eur Heart J 1989;10:159-67.

22. Kulik A, Le May MR, Voisine P, et al. Aspirin plus clopidogrel versus aspirin alone after coronary artery bypass grafting: the clopidogrel after surgery for coronary artery disease (CASCADE) Trial. Circulation 2010;122:2680-7.

23. Lorenz RL, Schacky CV, Weber M, et al. Improved aortocoronary bypass patency by low-dose aspirin $(100 \mathrm{mg}$ daily). Effects on platelet aggregation and thromboxane formation. Lancet 1984;1:1261-4.

24. Mannacio VA, Di Tommaso L, Antignan A, et al. Aspirin plus clopidogrel for optimal platelet inhibition following off-pump coronary artery bypass surgery: Results from the CRYSSA (prevention of Coronary arteRY bypaSS occlusion after off-pump procedures) randomised study. Heart 2012;98:1710-5.

25. Mayer JE Jr, Lindsay WG, Castaneda W, et al. Influence of aspirin and dipyridamole on patency of coronary artery bypass grafts. Ann Thorac Surg 1981;31:204-10.

26. Meister W, von Schacky C, Weber M, et al. Low-dose acetylsalicylic acid (100 mg/day) after aortocoronary bypass surgery: A placebo-controlled trial. Br J Clin Pharmacol 1984;17:703-11.

27. Saw J, Wong GC, Mayo J, et al. Ticagrelor and aspirin for the prevention of cardiovascular events after coronary artery bypass graft surgery. Heart 2016;102:763-9.

28. Brown BG, Cukingnan RA, DeRouen T. Improved graft patency in patients treated with platelet-inhibiting therapy after coronary bypass surgery. Circulation $1985 ; 72: 138-46$.
29. Sharma GV, Khuri SF, Josa M, et al. The effect of antiplatelet therapy on saphenous vein coronary artery bypass graft patency. Circulation 1983;68:II218-21.

30. Goldman S, Copeland J, Moritz T, et al. Saphenous vein graft patency 1 year after coronary artery bypass surgery and effects of antiplatelet therapy. Results of a Veterans Administration Cooperative Study. Circulation 1989;80:1190-7.

31. Buxton BF, Shi WY, Tatoulis J, et al. Total arterial revascularization with internal thoracic and radial artery grafts in triple-vessel coronary artery disease is associated with improved survival. J Thorac Cardiovasc Surg 2014;148:1238-43; discussion 1243-4.

32. Dimitrova KR, Hoffman DM, Geller CM, et al. Arterial grafts protect the native coronary vessels from atherosclerotic disease progression. Ann Thorac Surg 2012;94:475-81.

33. Deb S, Cohen EA, Singh SK, et al. Radial artery and saphenous vein patency more than 5 years after coronary artery bypass surgery: results from RAPS (Radial Artery Patency Study). J Am Coll Cardiol 2012;60:28-35.

34. Levine GN, Bates ER, Bittl JA, et al. 2016 ACC/ AHA Guideline Focused Update on Duration of Dual Antiplatelet Therapy in Patients With Coronary Artery Disease: A Report of the American College of Cardiology/American Heart Association Task Force on Clinical Practice Guidelines. J Am Coll Cardiol 2016;68:1082-115.

35. Members ATF, Kolh P, Windecker S, et al. 2014 ESC/ EACTS guidelines on myocardial revascularization: the task force on myocardial revascularization of the European Society of Cardiology (ESC) and the European Association for Cardio-Thoracic Surgery (EACTS) developed with the special contribution of the European Association of Percutaneous Cardiovascular Interventions (EAPCI). Eur J Cardiothorac Surg 2014;46:517-92.

36. Al Jaaly E, Zakkar M, Pufulete M, et al. Dual antiplatelet therapy after coronary artery bypass grafting: Do we have a consensus? J Integr Cardiol 2015;1:90-3.

37. Ibrahim K, Tjomsland O, Halvorsen D, et al. Effect of clopidogrel on midterm graft patency following off-pump coronary revascularization surgery. Heart Surg Forum 2006;9:E581-856.

38. Ebrahimi R, Bakaeen FG, Uberoi A, et al. Effect of aspirin plus clopidogrel therapy on aspirin resistance after offpump coronary artery bypass surgery. Ann Thorac Surg 2014;97:15-21.

39. Zhao Y, Peng H, Li X, et al. Dual antiplatelet therapy 
after coronary artery bypass surgery: is there an increase in bleeding risk? A meta-analysis. Interact Cardiovasc Thorac Surg 2018;26:573-82.

40. Limet R, David JL, Magotteaux P, et al. Prevention of

Cite this article as: Chakos A, Jbara D, Singh K, Yan TD, Tian DH. Network meta-analysis of antiplatelet therapy following coronary artery bypass grafting (CABG): none versus one versus two antiplatelet agents. Ann Cardiothorac Surg 2018;7(5):577585. doi: 10.21037/acs.2018.09.02 aorta-coronary bypass graft occlusion. Beneficial effect of ticlopidine on early and late patency rates of venous coronary bypass grafts: a double-blind study. J Thorac Cardiovasc Surg 1987;94:773-83. 


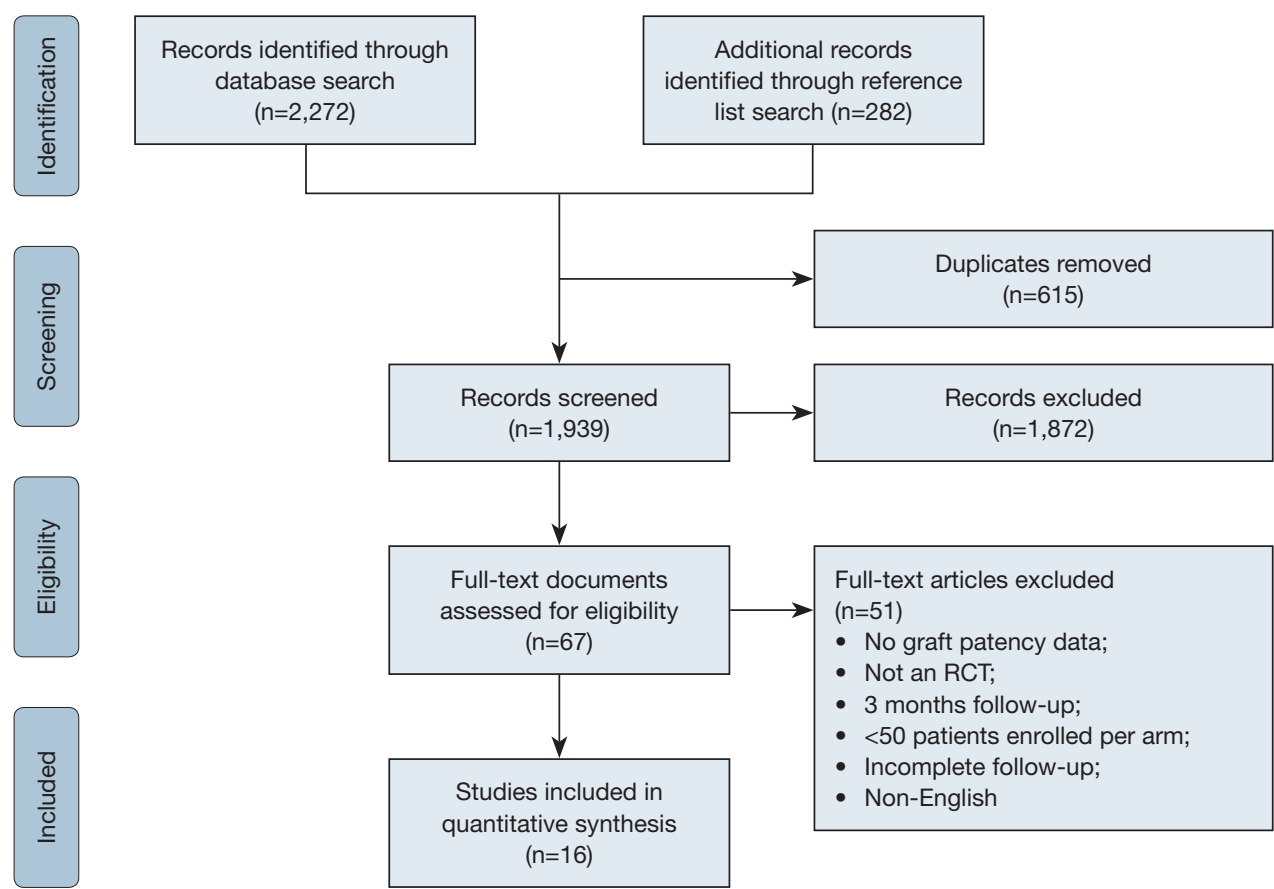

Figure S1 PRIMSA flow chart detailing the literature search process for randomized controlled trials comparing graft patency between placebo or drug arms. RCT, randomized controlled trial.

\begin{tabular}{|c|c|c|c|c|c|c|c|c|c|c|}
\hline Author, year published & Country & Recruitment period & RCT design & Quality & Mean f/u (months) & RCT arms & Post-op dose regimen & Graft type & On-pump (CCABG), off-pump (OPCAB) & Patients (n) \\
\hline \multirow[t]{2}{*}{ Brooks, 1985} & \multirow[t]{2}{*}{ England } & \multirow[t]{2}{*}{ 1978-1982 } & \multirow[t]{2}{*}{$\mathrm{s}$} & \multirow[t]{2}{*}{ SQ } & \multirow[t]{2}{*}{12.4} & Placebo & Placebo** & SVG & CCABG & 160 \\
\hline & & & & & & ASA + dipyridamole & ASA $330 \mathrm{mg}$ TDS + dipyridamole $75 \mathrm{mg}$ TDS & SVG & CCABG & 160 \\
\hline \multirow[t]{3}{*}{ Brown, 1985} & \multirow[t]{3}{*}{ USA } & \multirow[t]{3}{*}{$1976-1980$} & \multirow[t]{3}{*}{ S } & \multirow[t]{3}{*}{$H Q$} & \multirow[t]{3}{*}{12} & ASA + dipyridamole & ASA $325 \mathrm{mg}$ TDS + $75 \mathrm{mg}$ dipyridamole TDS & SVG & CCABG & 45 \\
\hline & & & & & & ASA & ASA $325 \mathrm{mg}$ TDS & SVG & CCABG & 38 \\
\hline & & & & & & Placebo & - & SVG & CCABG & 44 \\
\hline \multirow[t]{2}{*}{ Chesebro, 1984} & \multirow[t]{2}{*}{ USA } & \multirow[t]{2}{*}{$1977-1981$} & \multirow[t]{2}{*}{$\mathrm{s}$} & \multirow[t]{2}{*}{$H Q$} & \multirow[t]{2}{*}{$13.3 \pm 2.1^{*}$} & ASA + dipyridamole & ASA $325 \mathrm{mg}$ TDS & SVG & CCABG & 171 \\
\hline & & & & & & Placebo & NA & SVG & CCABG & 172 \\
\hline \multirow[t]{2}{*}{ Gao, 2009} & \multirow[t]{2}{*}{ China } & \multirow[t]{2}{*}{ 2005-2007 } & \multirow[t]{2}{*}{$\mathrm{s}$} & \multirow[t]{2}{*}{$\mathrm{HQ}$} & \multirow[t]{2}{*}{12} & Clopidogrel & $75 \mathrm{mg}$ clopidogrel OD & SVG, RA, LIMA & OPCAB, CCABG & 102 \\
\hline & & & & & & ASA + clopidogrel & ASA $100 \mathrm{mg}$ OD + $75 \mathrm{mg}$ clopidogrel OD & SVG, RA, LIMA & OPCAB, CCABG & 95 \\
\hline \multirow[t]{2}{*}{ Gao, 2010} & China & $2007-2008$ & $\mathrm{~s}$ & $H Q$ & 3 & ASA & ASA $100 \mathrm{mg}$ OD & LIMA, RA, SVG & OPCAB, CCABG & 111 \\
\hline & & & & & & ASA + clopidogrel & ASA $100 \mathrm{mg}$ OD + clopidogrel $75 \mathrm{mg}$ OD & LIMA, RA, SVG & OPCAB, CCABG & 113 \\
\hline Goldman, 1989 & USA & 1983-1986 & M & $H Q$ & 12 & Placebo & - & SVG & - & 107 \\
\hline & & & & & & ASA & ASA $325 \mathrm{mg}$ OD & SVG & - & 104 \\
\hline & & & & & & ASA & ASA $325 \mathrm{mg}$ TDS & SVG & - & 96 \\
\hline & & & & & & ASA + dipyridamole & ASA $325 \mathrm{mg}$ TDS + dipyridamole $75 \mathrm{mg}$ TDS & SVG & - & 99 \\
\hline Guiteras, 1989 & Spain & 1984-1986 & $\mathrm{s}$ & SQ & 6 & Placebo & - & LIMA, SVG & - & 68 \\
\hline & & & & & & ASA + dipyridamole & ASA $50 \mathrm{mg}$ TDS + dipyridamole $75 \mathrm{mg}$ TDS & LIMA, SVG & - & 72 \\
\hline Kulik, 2010 & Canada & $2006-2009$ & M & $H Q$ & 12 & ASA + clopidogrel & 162 mg ASA OD + 75 mg clopidogrel OD & SVG, LIMA, RIMA & CCABG, OPCAB & 56 \\
\hline & & & & & & ASA & ASA $162 \mathrm{mg}$ OD & SVG, LIMA, RIMA & CCABG, OPCAB & 57 \\
\hline Lorenz, 1984 & W. Germany & 1980-1982 & $\mathrm{s}$ & SQ & 4 & Placebo & - & SVG & CCABG & 31 \\
\hline & & & & & & ASA & ASA $100 \mathrm{mg}$ OD & SVG & CCABG & 29 \\
\hline Mannacio, 2012 & Italy & 2006-2009 & $\mathrm{s}$ & $\mathrm{HQ}$ & 12 & ASA & ASA $100 \mathrm{mg}$ OD & LIMA, RIMA, RA, SVG & CCABG, OPCAB & 150 \\
\hline & & & & & & ASA + clopidogrel & ASA $100 \mathrm{mg}$ OD + Clopidogrel $75 \mathrm{mg}$ OD & LIMA, RIMA, RA, SVG & CCABG, OPCAB & 150 \\
\hline Mayer Jr, 1981 & USA & 1973-1975 & $\mathrm{s}$ & SQ & 4.5 & ASA + dipyridamole & ASA $650 \mathrm{mg} \mathrm{BD} \mathrm{+} \mathrm{dipyridamole} 50 \mathrm{mg}$ BD & LIMA, SVG & CCABG & 47 \\
\hline & & & & & & Placebo & - & LIMA, SVG & CCABG & 66 \\
\hline McEnany, 1982 & USA & NR & $\mathrm{s}$ & $H Q$ & $22.8 \pm 13.3^{*}$ & Placebo & - & SVG & CCABG & 77 \\
\hline & & & & & & ASA & ASA $600 \mathrm{mg}$ BD & SVG & CCABG & 71 \\
\hline Meister, 1984 & W. Germany & 1980-1982 & $\mathrm{s}$ & $\mathrm{HQ}$ & 4 & Placebo & - & Unclear & CCABG & 31 \\
\hline & & & & & & ASA & ASA $100 \mathrm{mg}$ OD & Unclear & CCABG & 29 \\
\hline Saw, 2016 & Canada & 2011-2014 & M & $\mathrm{HQ}$ & 3 & ASA + ticagrelor & ASA $81 \mathrm{mg}$ OD + ticagrelor $90 \mathrm{mg} \mathrm{BD}$ & IMA, SVG, Radial & Unclear & 35 \\
\hline & & & & & & ASA & ASA $81 \mathrm{mg}$ OD & IMA, SVG, Radial & Unclear & 35 \\
\hline Sharma, 1983 & USA & 1977-1979 & $\mathrm{s}$ & SQ & 12 & Placebo & - & SVG & CCABG & 52 \\
\hline & & & & & - & ASA & ASA $325 \mathrm{mg}$ TDS & SVG & CCABG & 64 \\
\hline & & & & & 12 & ASA + dipyridamole & ASA $325 \mathrm{mg}$ TDS + dipyridamole 75 mg TDS & SVG & CCABG & 60 \\
\hline Van Der Meer, 1994 & Netherlands & 1987-1990 & M & $\mathrm{HQ}$ & - & ASA & ASA $50 \mathrm{mg}$ OD & IMA, SVG & NS & 173 \\
\hline & & & & & 12 & ASA + dipyridamole & ASA 50 mg OD + dipyridamole $200 \mathrm{mg}$ BD & IMA, SVG & NS & 163 \\
\hline
\end{tabular}

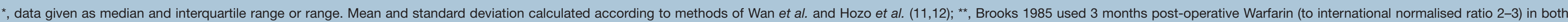

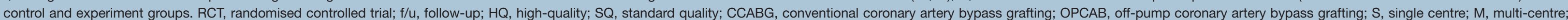

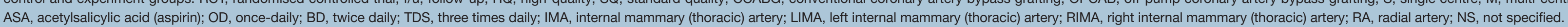




\begin{tabular}{|c|c|c|c|c|c|c|c|c|c|c|c|}
\hline Author, year published & Population & $\mathrm{RCT}$ arms & Patients (n) & Males (n) & Age $($ mean $\pm S D)$ & Smoking history (n) & HTN (n) & $\mathrm{HC}(\mathrm{n})$ & $\mathrm{DM}(\mathrm{n})$ & Prior MI (n) & Angina (n) \\
\hline \multirow[t]{2}{*}{ Brooks, 1985} & \multirow[t]{2}{*}{ SVG CABG } & Placebo & 160 & 143 & $51.3 \pm 12.8^{*}$ & 93 & 35 & - & 6 & 87 & 154 \\
\hline & & ASA + dipyridamole & 160 & 139 & $52.6 \pm 10.4^{\star}$ & 107 & 32 & - & 15 & 87 & 156 \\
\hline \multirow[t]{3}{*}{ Brown, 1985} & \multirow[t]{3}{*}{ SVG CABG } & ASA + dipyridamole & 45 & 45 & $52^{*}$ & - & - & - & - & - & - \\
\hline & & ASA & 38 & 38 & $52^{*}$ & - & - & - & - & - & - \\
\hline & & Placebo & 44 & 44 & $52^{*}$ & - & - & - & - & - & - \\
\hline Chesebro, 1984 & Primary cardiac CABG & ASA + dipyridamole & 171 & 155 & $53.3 \pm 10.2^{*}$ & 137 & 57 & - & - & - & 157 \\
\hline \multirow[t]{2}{*}{ Gao, 2009} & \multirow[t]{2}{*}{ Elective primary CABG } & Clopidogrel & 102 & 85 & $62.4 \pm 9.85$ & 48 & 66 & 20 & 51 & 49 & - \\
\hline & & ASA + clopidogrel & 95 & 78 & $60.5 \pm 10.11$ & 44 & 59 & 21 & 57 & 56 & - \\
\hline \multirow{2}{*}{ Gao, 2010} & \multirow{2}{*}{ Isolated CABG with >1 SVG } & ASA & 111 & 93 & $59.8 \pm 7.92$ & 66 & 63 & 44 & 45 & 49 & - \\
\hline & & ASA + clopidogrel & 113 & 93 & $57.9 \pm 8.25$ & 59 & 70 & 40 & 45 & 56 & - \\
\hline \multirow[t]{3}{*}{ Goldman, 1989} & \multirow[t]{3}{*}{ Elective male CABG } & Placebo & 107 & 107 & $58 \pm 8$ & 80 & 57 & - & - & 65 & 104 \\
\hline & & ASA & 104 & 104 & $59 \pm 8$ & 85 & 49 & - & - & 57 & 99 \\
\hline & & ASA & 96 & 96 & $59 \pm 7$ & 68 & 35 & - & - & 55 & 90 \\
\hline \multirow[t]{2}{*}{ Guiteras, 1989} & \multirow[t]{2}{*}{ SVG CABG } & Placebo & 68 & 47 & $56 \pm 8$ & 42 & 24 & - & 14 & 24 & 15 \\
\hline & & ASA + dipyridamole & 72 & 55 & $55 \pm 7$ & 42 & 20 & - & 19 & 31 & 14 \\
\hline \multirow[t]{2}{*}{ Kulik, 2010} & \multirow{2}{*}{ Isolated CABG with $\geq 2$ SVG } & ASA + clopidogrel & 56 & 51 & $64.9 \pm 7.5$ & 6 & 27 & 49 & 14 & 7 & - \\
\hline & & ASA & 57 & 50 & $68.1 \pm 7.4$ & 9 & 30 & 50 & 19 & 13 & - \\
\hline \multirow[t]{2}{*}{ Lorenz, 1984} & \multirow[t]{2}{*}{ Elective CABG } & Placebo & 31 & 28 & $54.6 \pm 6.2$ & 23 & - & - & - & - & 27 \\
\hline & & ASA & 29 & 24 & $55.1 \pm 10.3$ & 17 & - & - & - & - & 26 \\
\hline \multirow[t]{2}{*}{ Mannacio, 2012} & \multirow[t]{2}{*}{ OPCAB patients with at least $1 \mathrm{SVG}$} & ASA & 150 & 113 & $58.9 \pm 8.3$ & - & 68 & 86 & - & 52 & - \\
\hline & & ASA + clopidogrel & 150 & 110 & $59.4 \pm 7.7$ & - & 71 & 82 & - & 57 & - \\
\hline \multirow[t]{2}{*}{ Mayer Jr, 1981} & \multirow[t]{2}{*}{$C A B G$ for refractory angina pectoris } & ASA + dipyridamole & 47 & 36 & 56.2 & - & - & - & - & - & - \\
\hline & & Placebo & 66 & 57 & 52 & - & - & - & - & - & - \\
\hline \multirow[t]{2}{*}{ McEnany, 1982} & \multirow[t]{2}{*}{ 1-4 SVG CABG } & Placebo & 77 & 48 & $50.3 \pm 14.4^{*}$ & 12 & 11 & - & 7 & 35 & 47 \\
\hline & & ASA & 71 & 41 & $47.8 \pm 14.4^{*}$ & 20 & 13 & - & 7 & 29 & 45 \\
\hline \multirow[t]{2}{*}{ Meister, 1984} & All institute's patients enrolled & Placebo & 31 & 28 & 55 & 23 & 6 & 19 & - & 24 & 15 \\
\hline & & ASA & 29 & 24 & 55 & 17 & 6 & 12 & - & 17 & 11 \\
\hline Saw, 2016 & $18-80$ yo isolated ACS or stable CAD & ASA + ticagrelor & 35 & 30 & $61.7 \pm 7.5$ & 2 & 26 & 31 & 11 & 5 & 26 \\
\hline & & ASA & 64 & 64 & $52.5 \pm 11.6$ & 23 & 16 & 14 & 15 & 37 & - \\
\hline & & ASA + dipyridamole & 60 & 60 & $52.5 \pm 11.6$ & 21 & 14 & 11 & 13 & 32 & - \\
\hline Van Der Meer, 1994 & Elective CABG for angina & ASA & 173 & 154 & $58 \pm 9$ & 137 & 55 & 71 & 17 & - & 173 \\
\hline & & ASA + dipyridamole & 163 & 140 & $58 \pm 8$ & 127 & 55 & 57 & 15 & - & 163 \\
\hline
\end{tabular}


Table S3 Graft details and patency outcomes. Data for individual graft types was not completely reported, hence, for patency, overall figures are given

\begin{tabular}{|c|c|c|c|c|c|c|c|c|c|c|c|c|c|c|c|}
\hline \multirow{2}{*}{$\begin{array}{l}\text { Author, year } \\
\text { published }\end{array}$} & \multirow{2}{*}{ RCT arms } & \multirow{2}{*}{$\begin{array}{l}\text { Total grafts } \\
\text { (n) }\end{array}$} & \multirow{2}{*}{$\begin{array}{l}\text { Total grafts/ } \\
\text { patient (n) }\end{array}$} & \multirow{2}{*}{ SVG (n) } & \multirow{2}{*}{ LIMA (n) } & \multirow{2}{*}{$\operatorname{RIMA}(\mathrm{n})$} & \multirow{2}{*}{$\begin{array}{l}\text { Targets, } \\
\text { RA (n) }\end{array}$} & \multirow{2}{*}{$\operatorname{LAD}(n)$} & \multirow{2}{*}{$\operatorname{Diag}(n)$} & \multirow{2}{*}{ Circ $(n)$} & \multirow{2}{*}{$\mathrm{RCA}(\mathrm{n})$} & \multicolumn{2}{|c|}{ Per-GRAFT patency } & \multirow{2}{*}{ Total patency $(\mathrm{N} / \mathrm{n})$} & \multirow{2}{*}{ Total occluded (N/n) } \\
\hline & & & & & & & & & & & & Latest f/u (mo) & Assessment method & & \\
\hline \multirow[t]{2}{*}{ Brooks, 1985} & Placebo & 352 & 2.2 & 349 & 3 & - & - & - & - & - & - & 12 & CA & $306 / 352$ & - \\
\hline & ASA + dipyridamole & 360 & 2.25 & 358 & 2 & - & - & - & - & - & - & 12 & $\mathrm{CA}$ & $321 / 360$ & - \\
\hline \multirow[t]{3}{*}{ Brown, 1985} & ASA + dipyridamole & 138 & 3.1 & 138 & - & - & - & - & - & - & - & 12 & $\mathrm{CA}$ & - & $19 / 138$ \\
\hline & ASA & 114 & 3.1 & 114 & - & - & - & - & - & - & - & 12 & CA & - & $14 / 114$ \\
\hline & Placebo & 147 & 3.3 & 147 & - & - & - & - & - & - & - & 12 & $\mathrm{CA}$ & - & $31 / 147$ \\
\hline \multirow[t]{2}{*}{ Chesebro, 1984} & ASA + dipyridamole & 355 & 2.1 & 171 & - & - & - & $98^{*}$ & 9 & 70 & 92 & 12 & $\mathrm{CA}$ & - & $24 / 270$ \\
\hline & Placebo & 345 & 2 & 172 & - & - & - & 93 & 5 & 72 & 85 & 12 & $\mathrm{CA}$ & - & $75 / 256$ \\
\hline \multirow[t]{2}{*}{ Gao, 2009} & Clopidogrel & 252 & $2.49 \pm 0.72$ & 154 & 98 & - & - & 98 & - & - & - & 12 & CTA & $239 / 252$ & - \\
\hline & ASA + clopidogrel & 253 & $2.66 \pm 0.75$ & 163 & 90 & - & - & 90 & - & - & - & 12 & $\mathrm{CA}$ & $245 / 253$ & - \\
\hline \multirow[t]{2}{*}{ Gao, 2010} & ASA & 340 & 3.11 & 233 & 109 & - & 3 & 110 & 56 & 131 & 119 & 3 & CTA & $305 / 340$ & $35 / 340$ \\
\hline & ASA + clopidogrel & 353 & 3.18 & 242 & 112 & - & 5 & 112 & 61 & 133 & 121 & 3 & CTA & $330 / 353$ & $23 / 353$ \\
\hline \multirow[t]{4}{*}{ Goldman, 1989} & Placebo & 345 & $3.22^{*}$ & 345 & - & - & - & - & - & - & - & 12 & $\mathrm{CA}$ & - & $78 / 345$ \\
\hline & ASA & 340 & $3.27^{\star}$ & 340 & - & - & - & - & - & - & - & 12 & CA & - & $45 / 340$ \\
\hline & ASA & 315 & $3.28^{*}$ & 315 & - & - & - & - & - & - & - & 12 & $\mathrm{CA}$ & - & $53 / 315$ \\
\hline & ASA + dipyridamole & 315 & $3.18^{*}$ & 315 & - & - & - & - & - & - & - & 12 & $\mathrm{CA}$ & - & $55 / 315$ \\
\hline \multirow[t]{2}{*}{ Guiteras, 1989} & Placebo & 94 & $2.3 \pm 0.8$ & - & - & - & - & - & - & - & - & 6 & $\mathrm{CA}$ & - & $12 / 94 /$ \\
\hline & ASA + dipyridamole & 116 & $2.4 \pm 0.8$ & - & - & - & - & - & - & - & - & 6 & $\mathrm{CA}$ & - & $10 / 116$ \\
\hline Kulik, 2010 & ASA + clopidogrel & 136 & $2.96^{\star}$ & 57 & 57 & 14 & - & - & - & - & - & 12 & $\mathrm{CA}$ & - & $7 / 136^{*}$ \\
\hline & ASA & 121 & $2.75^{\star}$ & 87 & 85 & 12 & - & - & - & - & - & 12 & $\mathrm{CA}$ & - & $5 / 121^{*}$ \\
\hline Lorenz, 1984 & Placebo & 53 & 2.23 & - & - & - & - & 23 & - & 15 & 15 & 4 & CA & - & $17 / 53$ \\
\hline & ASA & 40 & 1.9 & - & - & - & - & 19 & - & 13 & 8 & 4 & $\mathrm{CA}$ & - & $4 / 40 /$ \\
\hline Mannacio, 2012 & ASA & 267 & $3.2 \pm 0.6$ & 267 & 141 & 35 & 24 & 144 & 51 & 137 & 135 & 12 & CTA & - & $35 / 267$ \\
\hline & ASA + clopidogrel & 257 & $3.1 \pm 0.6$ & 257 & 142 & 28 & 28 & 144 & 40 & 141 & 130 & 12 & CTA & - & $19 / 257$ \\
\hline Mayer Jr, 1981 & ASA + dipyridamole & 93 & 1.9 & 75 & - & - & - & - & - & - & - & $3-6$ & CA & $87 / 93$ & - \\
\hline & Placebo & 120 & 1.9 & 92 & - & - & - & - & - & - & - & $3-6$ & $\mathrm{CA}$ & $98 / 120$ & - \\
\hline McEnany, 1982 & Placebo & 74 & $1.34^{*}$ & - & - & - & - & - & - & - & - & $12-24$ & $\mathrm{CA}$ & $54 / 74$ & - \\
\hline & ASA & 81 & $1.44^{*}$ & - & - & - & - & - & - & - & - & $12-24$ & CA & $65 / 81$ & - \\
\hline Meister, 1984 & Placebo & 53 & $1.71^{*}$ & - & - & - & - & - & - & - & - & 4 & $\mathrm{CA}$ & $36 / 53$ & - \\
\hline & ASA & 40 & $1.38^{*}$ & - & - & - & - & - & - & - & - & - & $\mathrm{CA}$ & $36 / 40$ & - \\
\hline Saw, 2016 & ASA + Ticagrelor & 87 & $2.49^{*}$ & 40 & 40 & - & 7 & - & - & - & - & 3 & CTA & - & $9 / 87$ \\
\hline & ASA & 120 & $3.43^{*}$ & 59 & 51 & - & 10 & - & - & - & - & 3 & CTA & - & $22 / 120$ \\
\hline Sharma, 1983 & Placebo & 95 & 2.2 & - & - & - & - & 30 & 10 & - & 27 & 12 & $C A$ & $76 / 95$ & - \\
\hline & ASA & 111 & 2.2 & - & - & - & - & 36 & 12 & - & 30 & 12 & CA & $87 / 111$ & - \\
\hline & ASA + dipyridamole & 89 & 1.9 & - & - & - & - & 29 & 13 & - & 24 & 12 & CA & $74 / 89$ & - \\
\hline Van Der Meer, 1994 & ASA & 157 & $1.05^{\star}$ & - & 157 & - & - & 144 & 57 & 10 & 0 & 12 & $\mathrm{CA}$ & - & $10 / 157$ \\
\hline & ASA + dipyridamole & 139 & $1.12^{*}$ & - & 139 & - & - & 126 & 33 & 18 & 0 & 12 & CA & - & $7 / 139$ \\
\hline
\end{tabular}

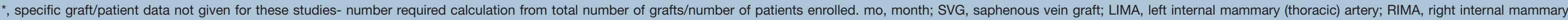

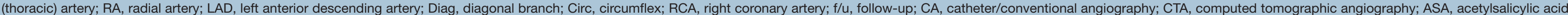
(aspirin). 


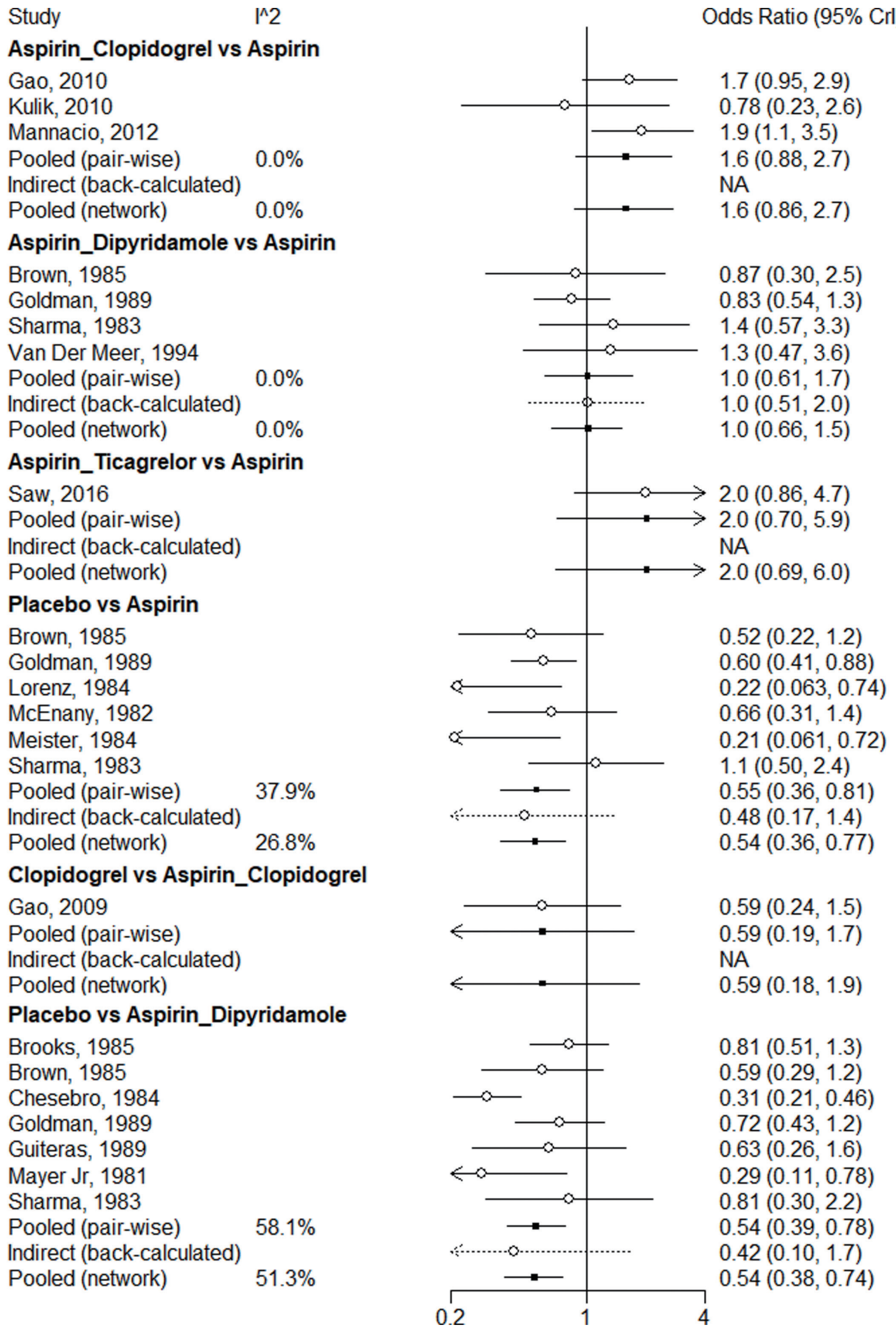

Figure S2 Direct, indirect and pooled network comparisons between treatments using a random effects model. Heterogeneity is shown for comparisons with at least 2 sets of direct evidence. ASA, aspirin; CrI, credible interval. 

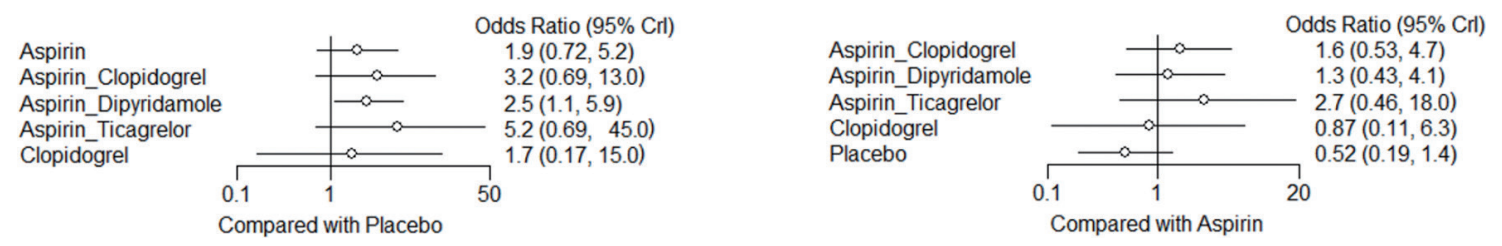

Figure S3 Sub-group analysis of saphenous vein graft (SVG) patency between different agents from 8 of 16 included studies. Placebo and aspirin used as reference.

\begin{tabular}{|c|c|c|c|c|c|c|}
\hline Author, year published & RCT arms & Patients (n) & Death (n) & Bleeding (n) & $\mathrm{Ml}(\mathrm{n})$ & CVA (n) \\
\hline \multirow[t]{2}{*}{ Brooks, 1985} & Placebo & 160 & 3 & 2 & - & - \\
\hline & ASA + dipyridamole & 160 & 2 & 3 & - & - \\
\hline \multirow[t]{3}{*}{ Brown, 1985} & ASA + dipyridamole & 45 & 1 & - & - & 0 \\
\hline & ASA & 38 & 1 & - & - & 1 \\
\hline & Placebo & 44 & 1 & - & - & 1 \\
\hline \multirow[t]{2}{*}{ Chesebro, 1984} & ASA + dipyridamole & 171 & - & - & - & - \\
\hline & Placebo & 172 & - & - & - & - \\
\hline \multirow[t]{2}{*}{ Gao, 2009} & Clopidogrel & 102 & 0 & 0 & 0 & - \\
\hline & ASA + clopidogrel & 95 & 0 & 0 & 0 & - \\
\hline \multirow[t]{2}{*}{ Gao, 2010} & ASA & 111 & 1 & - & - & - \\
\hline & ASA + clopidogrel & 113 & 0 & - & - & - \\
\hline \multirow[t]{4}{*}{ Goldman, 1989} & Placebo & 107 & 2 & - & 1 & - \\
\hline & ASA & 104 & $9^{\star \star}$ & - & $12^{\star \star}$ & - \\
\hline & ASA & 96 & - & - & - & - \\
\hline & ASA + dipyridamole & 99 & - & - & - & - \\
\hline \multirow[t]{2}{*}{ Guiteras, 1989} & Placebo & 68 & 3 & - & 0 & - \\
\hline & ASA + dipyridamole & 72 & 3 & - & 0 & - \\
\hline \multirow[t]{2}{*}{ Kulik, 2010} & ASA + clopidogrel & 56 & 0 & 4 & 4 & 0 \\
\hline & ASA & 57 & 1 & 3 & 1 & 2 \\
\hline \multirow[t]{2}{*}{ Lorenz, 1984} & Placebo & 31 & - & - & - & - \\
\hline & ASA & 29 & - & - & - & - \\
\hline \multirow[t]{2}{*}{ Mannacio, 2012} & ASA & 150 & 2 & 4 & 6 & 4 \\
\hline & ASA + clopidogrel & 150 & 1 & 5 & 3 & 2 \\
\hline \multirow[t]{2}{*}{ Mayer Jr, 1981} & ASA + dipyridamole & 47 & - & - & - & - \\
\hline & Placebo & 66 & - & - & - & - \\
\hline \multirow[t]{2}{*}{ McEnany, 1982} & Placebo & 77 & 3 & 0 & 5 & - \\
\hline & ASA & 71 & 1 & 0 & 1 & - \\
\hline \multirow[t]{2}{*}{ Meister, 1984} & Placebo & 31 & 2 & - & 1 & 1 \\
\hline & ASA & 29 & 2 & - & 0 & 0 \\
\hline \multirow[t]{2}{*}{ Saw, 2016} & ASA + ticagrelor & 35 & 0 & 1 & 0 & 0 \\
\hline & ASA & 35 & 1 & 0 & 0 & 0 \\
\hline \multirow[t]{3}{*}{ Sharma, 1983} & Placebo & 52 & 0 & - & - & - \\
\hline & ASA & 64 & 0 & - & - & - \\
\hline & ASA + dipyridamole & 60 & 0 & - & - & - \\
\hline \multirow[t]{2}{*}{ Van Der Meer, 1994} & ASA & 173 & 3 & 10 & 15 & - \\
\hline & ASA + dipyridamole & 163 & 3 & 13 & 15 & - \\
\hline
\end{tabular}

